\title{
Gradient Perfusion Culture - Simulating a Tissue-Specific Environment for Epithelia in Biomedicine
}

\author{
Will W. Minuth*, Lucia Denk and Anne Roessger
}

Molecular and Cellular Anatomy, University of Regensburg, Regensburg, Germany

\begin{abstract}
Epithelia act in the organism as biological barriers. All of them are exposed to different environments at the luminal and basal side. To simulate such a tissue-specific situation Minusheet ${ }^{\circledR}$ gradient perfusion culture was developed. For pharmaceutical research, biomaterial testing and tissue engineering epithelial cells are cultured on individually selected supports (1). Growing epithelia are stabilized within a tissue carrier (2). Long term culture is performed in a gradient perfusion container (3). To expose epithelia to a tissue-specific environment fresh media of different composition are transported parallel to the luminal and basal compartment of the gradient container. During culture leakage, edge damage and pressure differences have to be avoided. Harvest of intact epithelia is promoted by the use of biocompatible supports and innovative equipment such as transport of oxygen-rich and gas bubble-free medium. Actual literature demonstrates that gradient perfusion culture is an effective method to investigate barrier functions under realistic conditions. Examples of application comprise renal epithelia, retina, blood-air barrier, blood-brain barrier including aspects of tissue-specific development and regeneration.
\end{abstract}

Keywords: Epithelia, gradient perfusion culture, barrier, biomaterial testing, pharmaceutical research, tissue engineering, differentiation.

\section{EPITHELIAL BARRIERS}

Beside the nervous tissue, the muscular tissue and the connective tissue epithelia belong to the fourth group of basic tissues in the organism. All of the epithelia exhibit important barrier functions. They are heterogeneously composed, consist as simple, pseudostratified or stratified epithelia and contain squamous, cuboidal or columnar cells. The tasks of epithelia are manifold. The protection of underlying tissues is the role of epithelium covering the external surfaces and orifices, while transport of mucus and particles is performed by ciliated epithelia found in secretory, respiratory and genital ducts. The epithelia of the intestine, liver and kidney are involved in absorption, secretion and filtering of molecules from and into a lumen. In follicles of the thyroid gland and ovary the relation of the epithelia to a free surface is retained. Taste buds and olfactory mucosa epithelia are involved in sensory reception. Typical for all of the epithelia is that they rest on a layer of extracellular matrix called basement membrane or basal lamina.

\section{NEED OF EPITHELIAL MODELS}

An epithelium acts always as a physiological barrier separating and controlling the exchange of molecules between the luminal and basal side. To investigate the development of these polarized functions, to improve the adhesion of cells on new biomaterials or to analyze the metabolism of newly developed pharmaceuticals cultures with epithelial cells are of great importance in biomedical research. For example, to elaborate typical cell biological functions

*Address correspondence to this author at the Molecular and Cellular Anatomy, University of Regensburg, Universitätstrasse 31, D - 93053 Regensburg, Germany; Tel: +49 (0) 941943 2876; Fax: +49 (0) 941943 2868; E-mail: will.minuth@vkl.uni-regensburg.de cultures were prepared from skin [1-5], endothelium [6-9] and organ parenchyme $[10,11]$ such as liver [12-14] or lung [15-17]. Cultures from urothelial [18-21], esophageal [2225] and tracheal [26-31] epithelium revealed to be important model tissues for optimizing the differentiation profile in tissue engineering.

\section{DIFFERENTIATION VERSUS DEDIFFERENTIA- TION}

Despite numerous efforts cultured epithelia often do not develop the necessary degree of functionality [32-34]. The reason is the very sensitive reaction of isolated epithelial cells to environmental influences. It was shown for example that the differentiation of cultured epithelia is highly dependent on selected biomaterials [35-37], cellular attachment [3840], intercellular communication [41-43] and the environmental conditions during culture [44-48]. All these factors have to complement one another in order to support an optimal differentiation, while preventing the development of atypical features by dedifferentiation. Thus, the culture under tissue-specific conditions is an essential presupposition to reach a high degree of differentiation, since correct functionality is needed in biomaterial testing, tissue engineering and pharmaceutical research [35, 49-55].

\section{FINDING A COMFORT ENVIRONMENT}

Adult epithelia from skin, lung and cornea are exposed to air at the luminal and fluid at the basal side. All other epithelia act as a functional barrier between two differently composed fluids at their luminal and basal side. Only during fetal development epithelial cells are exposed to an environment consisting of the same fluid composition at the luminal and basal side (Fig. 1a). This situation changes during maturation as neighboring cells develop intercellular junctions. The lu- 
minal and basal sides of the epithelium become polarized and a functional barrier develops (Fig. 1b). Yet the epithelia start to be exposed to different environments. Such mature epithelia exhibit continuous barrier functions throughout their life span and control thereby the transport of molecules from one side to the other.
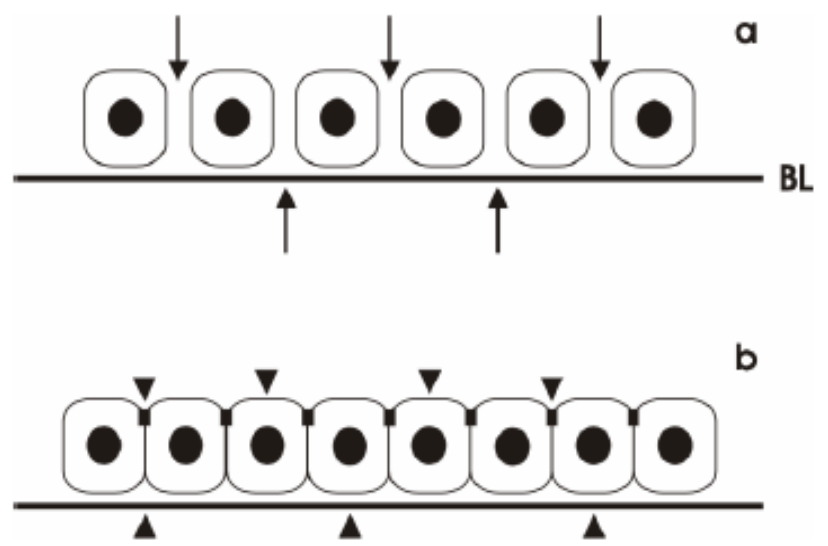

Fig. (1). Schematic illustration of epithelial development. (a) An immature epithelium does not provide a barrier function. The junctional belt is not fully developed, therefore the uncontrolled passage of molecules is possible via the paracellular shunt (short arrows). (b) In the matured state the tight junctions are sealing and the paracellular shunt is closed. The epithelial barrier is yet intact and the epithelial cells mediate selective passage of molecules (arrow head). BL basal lamina.

To investigate specific features epithelial cells can be cultured in classical culture dishes. When a serum-containing medium is used, the cells adhere to the polystyrene surface, divide and sprout out until a more or less confluent monolayer is established (Fig. 2a). However, in most of the cases it is observed that the sprouting cells do not develop the required degree of polarization and functionality when growing in this environment. A limiting factor is the unequal distribution of nutrients and oxygen supply. One side of the epithelial cells is resting on the bottom of the dish, where a significantly reduced supply of nutrients and oxygen is found as compared to the side facing the culture medium. Comparing the bottom of a culture dish with the site of origin this is a non-physiological situation for the growing cells, which in turn does not promote the development of polarization.

To improve the culture environment for epithelia filter inserts can be applied [23,56-60]. The cells grow on a filter, which is fixed on a cylinder. Offering a culture medium the epithelial cells are now exposed to an equal distribution of nutrients and oxygen supply at the luminal and basal sides. As long the cells are non-confluent a free exchange beween the luminal and basal sides of the epithelium is given (Fig. 2b). However, a non-controlled mixing of media between the luminal and basal side of the epithelial cell layer represents a non-physiological situation and results in an un-typical biological short circuit current.

When a confluent cell monolayer is reached, the epithelium can now be provided with media of different electrolyte composition at the luminal and basal side. Yet, full polarization and transport features are up-regulated, which can be registered as trans-epithelial potential difference respectively resistance in physiological set-ups (Fig. 2c). However, the long term maintenance of epithelia in a filter insert cultured in a fluid gradient is problematic due to the stagnant environment and the un-equal volume of medium fluid between the luminal (small) and basal (big) compartment. In consequence, a continuous fluid gradient between the luminal und basal side of the epithelium cannot be maintained over prolonged periods of time in the stagnant environment of a culture dish.
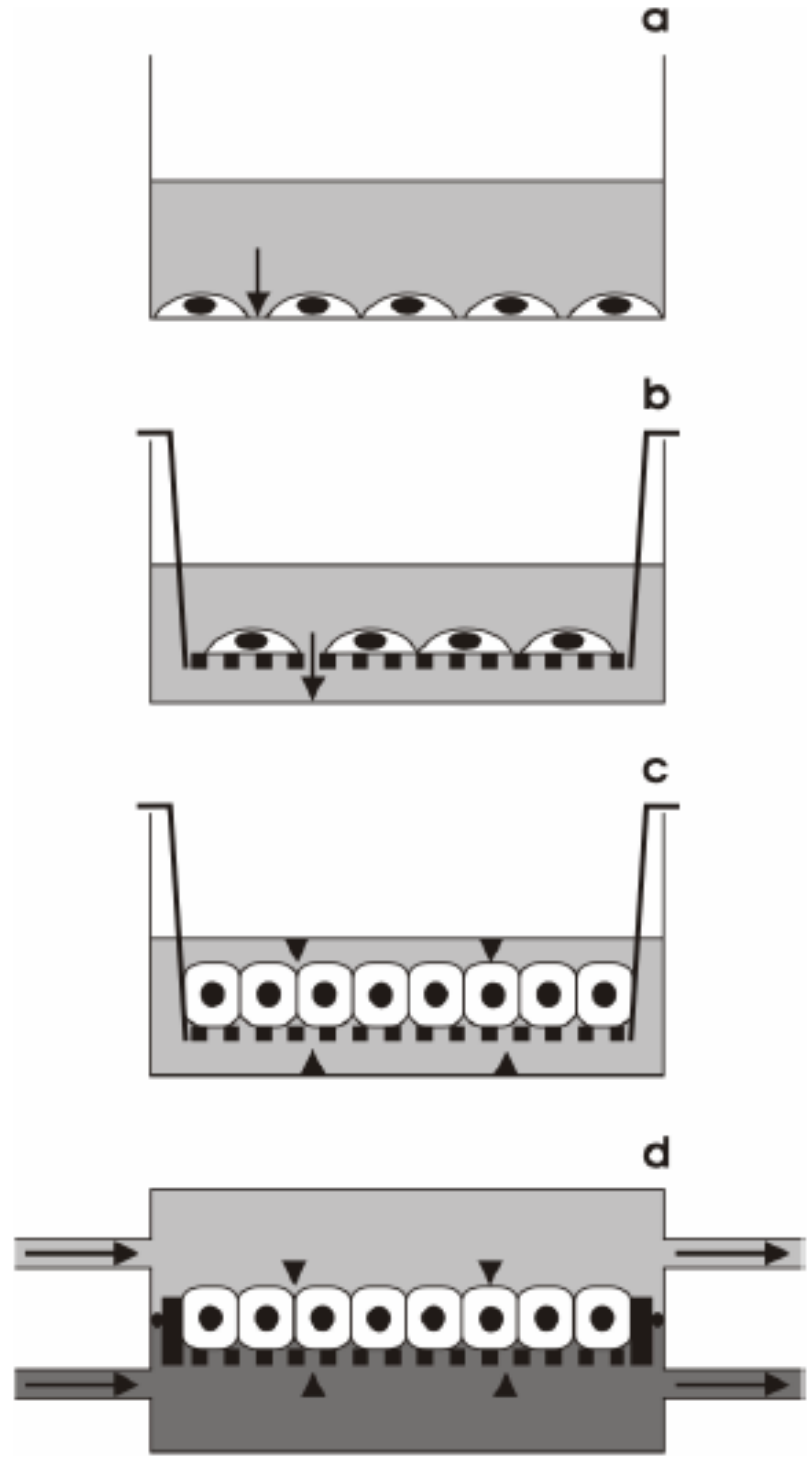

Fig. (2). Schematic illustration of different culture conditions for epithelia. (a) Suboptimal development of epithelial cells at the bottom of a culture dish. (b) Non-confluent epithelial cells cultured in a filter insert. (c) Confluent epithelial cells cultured in a filter insert. (d) Confluent epithelial cells cultured on a support within a tissue carrier inside a gradient container with constant luminal and basal transport of fresh medium (long arrows). The leaky barrier is demonstrated by short arrows, while the intact epithelial barrier is indicated by arrow heads.

\section{CONTINUOUS FLUID GRADIENT}

To provide epithelia by a continuous flow of always fresh media at the luminal and basal side gradient perfusion cul- 
ture has to be applied (Fig. 2d). Since such a technique was commercially not available, a special system was designed, machined and continuously improved [61-63]. Over prolonged periods of time the developed gradient perfusion culture technique should meet the individual needs for epithelia resulting in a high degree of cellular differentiation [64-67].

During construction of equipment for gradient perfusion culture multiple experimental steps had to be taken into consideration, for example to understand how to maintain epithelia as a living barrier in a permanent fluid gradient over a longer space of time. In this context it was necessary to learn about close adherence of epithelial cells on selected biomaterials used as mechanical support and to investigate problems related to resistance to fluid stress. During gradient perfusion culture the epithelia have to tolerate different fluid composition at the luminal and basal side over prolonged periods of weeks maintaining differentiation and epithelial barrier function. Specific conditions are now elaborated for different types of epithelia so that they develop in gradient perfusion culture cell biological features closely resembling their functional counterparts found within the organism. This was achieved by solving technical needs in combination with cell biological requirements [63]. Performance of gradient perfusion culture appears quite simple at first sight. However, closer examination reveals that it is a sophisticated technique, which requires knowledge, experience and extensive practise in order to generate intact epithelia in long term culture experiments.

\section{TECHNICAL REQUIREMENTS}

In the organism epithelia are continuously supplied with fresh nutrients and oxygen, while metabolic waste products are eliminated. To offer such a physiological environment under in vitro conditions on the one hand technical equipment is required, on the other hand the development of a sealing epithelium within the gradient perfusion culture container is essential. The sealing of an epithelium in turn depends on an optimal adherence and confluent growth of cells on a selected support material, which occurs on a tissue carrier placed inside a gradient perfusion culture container. Thus, only an optimal interaction between the technical equipment and the growing epithelial cells results in the development of an intact physiological barrier.
The generation of functional epithelia in a gradient perfusion culture container is an interactive process. It depends on:

1. Adherence of cells on an individually selected support (Fig. 3a).

2. Protection of growing cells within a Minusheet ${ }^{\circledR}$ tissue carrier (Figs. 3b, c).

3. Culture of epithelia in a gradient perfusion container (Figs. 4, 5, 6 e,f).

4. Transport of oxygenated but bubble-free medium (Fig. 6).

\section{Avoiding pressure differences (Figs. 7, 8).}

\section{Selection of an Individual Support}

In gradient perfusion culture epithelia have to resist fluid stress and media of different composition at the luminal and basal side. One of the prerequisites for an optimal epithelial development is therefore the positive interaction of cells with a support selected as a basal lamina substitute. To obtain a perfect confluent growth of cells the support has to show complete biocompatibility [64-68]. The spectrum of prospective materials is broad. More rigid support materials such as nitrocellulose, polycarbonate or polyester are available in form of membranes, foils or meshes. All of these materials are applied to improve the mechanical stability and to promote differentiation of the cultured epithelium. Rigid materials such as nitrocellulose or polycarbonate can better withstand deformation during fluid stress resulting from pressure differences in the gradient perfusion culture container. The selected support has to be permeable and should have enough porosity allowing free exchange of molecules (pores $>0.2 \mu \mathrm{m}$ ). Many of described materials are commercially available as discs measuring $13 \mathrm{~mm}$ in diameter. Other materials have to be excised by a punching tool in order to fit into a tissue carrier. Finally, before cell seeding the selected support has to withstand a sterilization procedure without loosing its specific properties for cell adherence.

\section{Support within a Tissue Carrier}

In order to prevent damage of the growing epithelial cells the selected support is transferred to a tissue carrier made of Procan ${ }^{\mathbb{B}}$ (Fig. 3a). For mounting the support is placed for
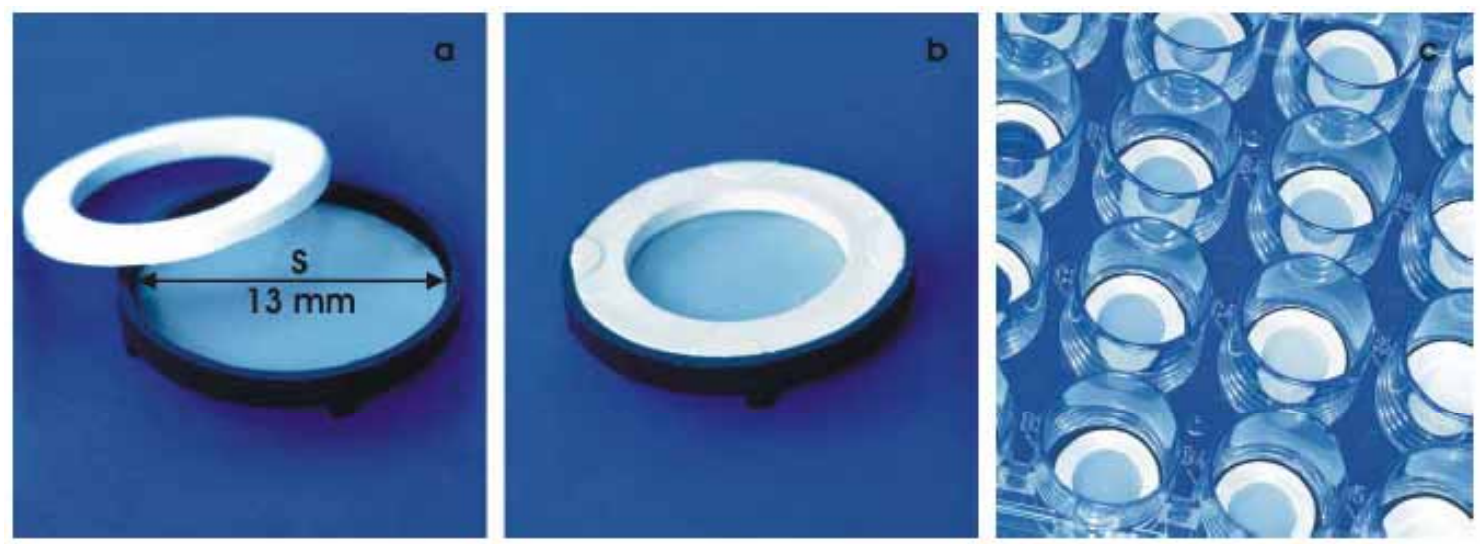

Fig. (3). Illustration of a tissue carrier used inside a gradient perfusion culture container. (a) A suitable biomaterial such as filters with 13 $\mathrm{mm}$ diameter is placed in a holder (black) and fixed by a tension ring (white). (b) Surface view on a mounted tissue carrier. (c) Adherence of cells is performed in a 24 -well culture plate. 
example into the lower part (black) of a Minusheet ${ }^{\circledR}$ tissue carrier and is stabilized by a tension ring (white) (Fig. 3b). Another type of tissue carrier can hold flexible sheets of natural extracellular matrices (not shown). In this case the material is held in place by a silicone ring like the skin of a drum. In both cases the fixation within a tissue carrier leads to an exact orientation, stabilizes the developing epithelium, prevents mechanical damage and facilitates handling during transport.

The tissue carrier is resting on small protrusions. It allows medium supply at the luminal und basal side, when used for cell seeding at the bottom of a culture dish (Fig. 3c). Since a tissue carrier is flat, it can be turned the way that seeding of cells on both sides for co-culture experiments becomes possible.

\section{Gradient Perfusion Culture Container}

A gradient container is CAD-constructed and $\mathrm{CNC}$ machined out of polycarbonate $\left(\right.$ Makrolon $\left.^{\circledR}\right)$ in a specialized work shop (Minucells and Minutissue, Bad Abbach, Germany). During fabrication the machined surfaces are treated with a specific lubricant. This treatment makes the inner surfaces of the container non-attractive for cell attachment and causes cells to grow exclusively on the support and not to spread across the tissue carrier. A gradient container typically can hold 1 (Fig. 4a,b) or 6 (Fig. 4c,d) tissue carriers. The flat form of a tissue carrier guarantees an exact geometrical placement of the growing epithelium within a gradient perfusion culture container. This specific construction facilitates the uniform supply of medium to the luminal and basal sides. Gradient culture experiments under visual control can be performed using a special microscope container (Fig. 4e,f). In this case the tissue carrier with a diameter of $13 \mathrm{~mm}$ is mounted between a transparent lid and base part.

In a gradient perfusion culture container (Fig. 4) the tissue carrier is held in place between the base part and the lid (Fig. 2d). By this principle of construction the luminal and basal side can be provided with individual media mimicking a tissue-specific environment for epithelia. Fresh culture medium is continuously transported into the gradient container at one side, while the metabolized medium is removed to the other side.

\section{Housing}

Gradient perfusion culture experiments are performed under room atmosphere at a constant temperature of usually $37^{\circ} \mathrm{C}$. This can be achieved by placing the gradient perfusion culture container onto a thermo plate (MEDAX-Nagel, Kiel, Germany) covered by a removable lid (Fig. 5).

\section{SELECTION OF MEDIA}

Gradient perfusion culture can be performed principally with all culture media. Publications from several laboratories show that gradient perfusion culture was successfully performed with HBSS, DMEM, IMDM or others [67, 69-71]. Depending on the experimental design some of the media contain serum as a supplement, while in other series serumfree media are applied. The typical medium used for gradient perfusion culture in our laboratory is serum-free Iscove's modified Dulbecco`s medium (IMDM; order \# 21980 - 032; Gibco/Invitrogen, Karlsruhe, Germany) for embryonic collecting duct (CD) epithelia derived from renal stem/progenitor cells $[64,66,67]$. In this case aldosterone $(1 \mathrm{x}$ $10^{-7} \mathrm{M}$; Sigma-Aldrich Chemie, Munich, Germany) is added
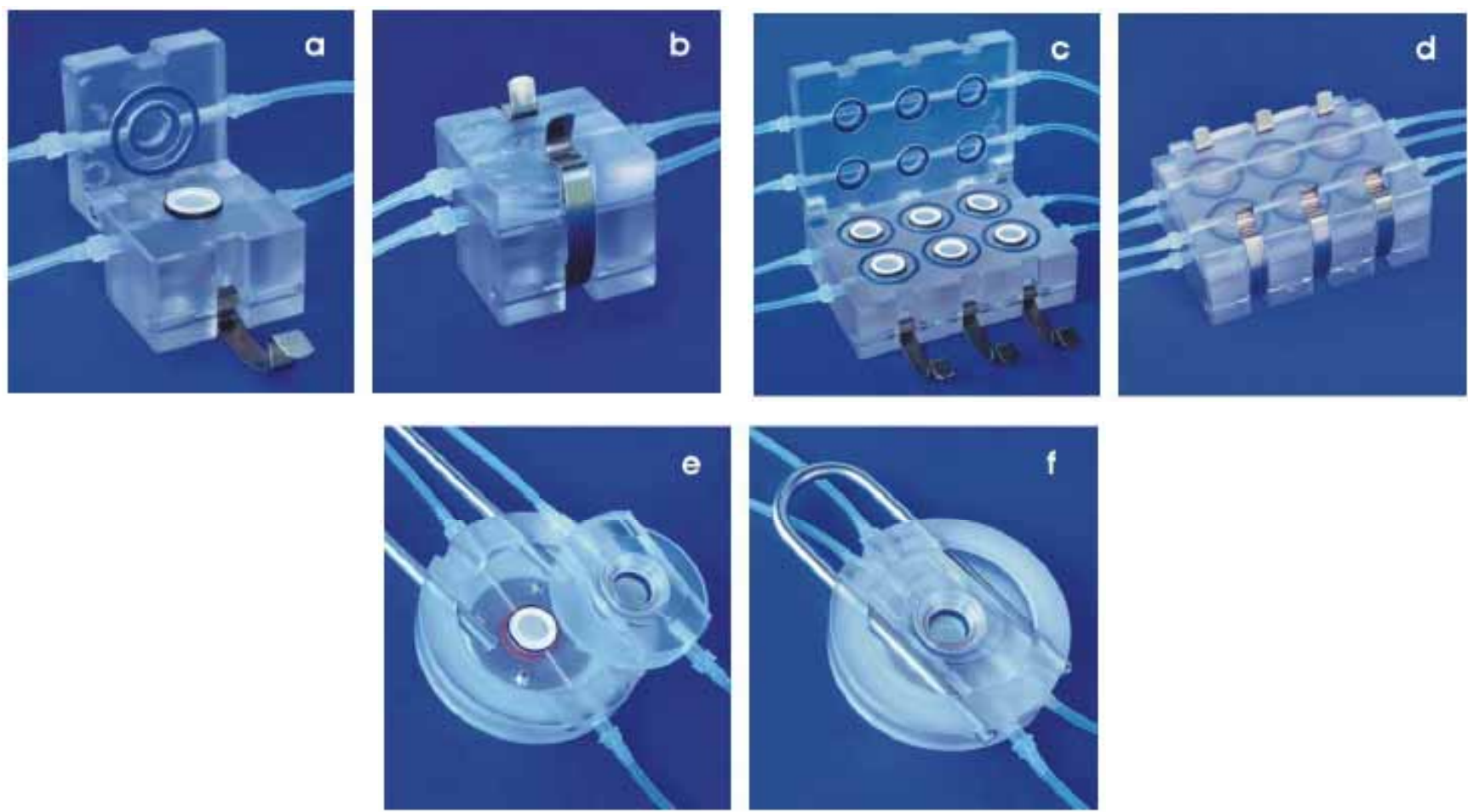

Fig. (4). Photographs showing different kinds of gradient perfusion culture containers. Each gradient perfusion culture container consists of a basal and upper part. The tissue carrier is placed in the space inbetween. (a - d) A gradient container typically can hold 1 (a, b) or 6 (c, d) tissue carriers. (e, f) Gradient culture experiments under visual control are performed by a special microscope container. 


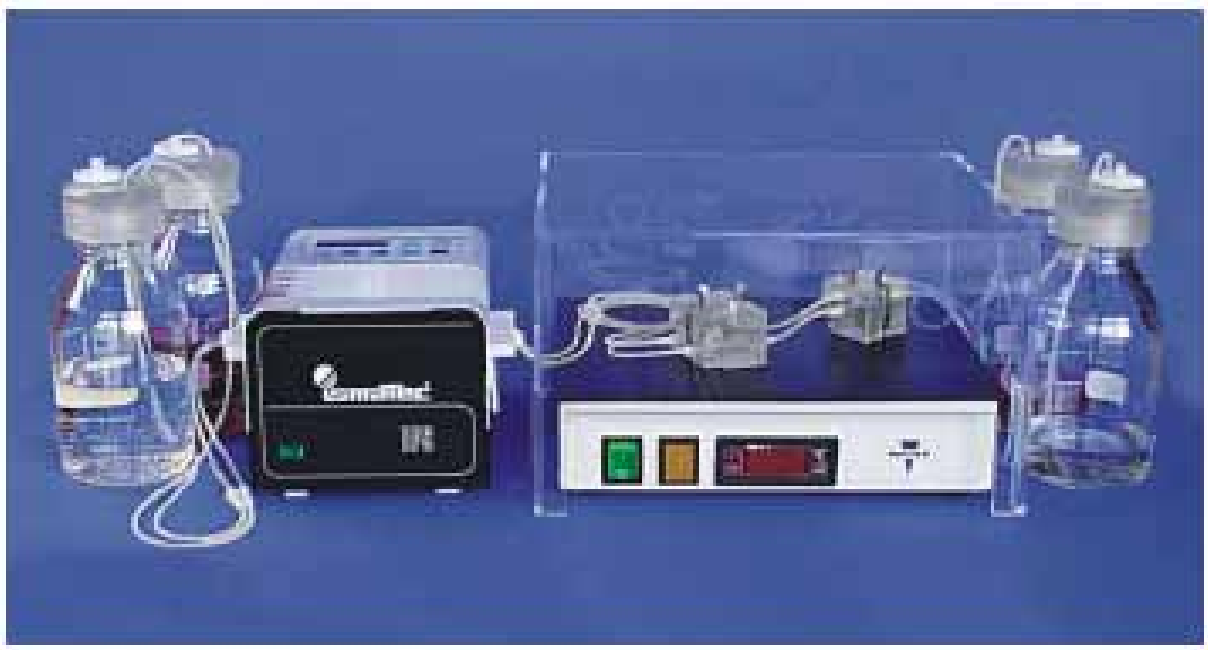

Fig. (5). Gradient perfusion culture is performed on a laboratory table. A peristaltic pump (left side) transports the media (1 ml/h) from the storage bottles to a gas expander module and onward to a gradient container. The waste medium is collected in the bottles on the right side. A heating plate and a lid maintain the desired temperature.

as tubulogenic factor and $1 \%$ antibiotic-antimycotic solution (Gibco/Invitrogen) is used to prevent growth of microorganisms.

\section{Maintenance of Correct pH}

Conventional culture media for the use in a $\mathrm{CO}_{2}$ incubator are normally buffered by a system containing a defined amount of $\mathrm{NaHCO}_{3}, 95 \%$ air and $5 \% \mathrm{CO}_{2}$ to maintain a constant $\mathrm{pH}$ of 7.4. When such a buffer system is used in gradient perfusion culture outside a $\mathrm{CO}_{2}$-incubator under room atmosphere $\left(0.3 \% \mathrm{CO}_{2}\right), \mathrm{pH}$ will shift out of the physiological into the alkaline range. In consequence, the medium has to be stabilized by reducing the $\mathrm{NaHCO}_{3}$ content and/or by adding a biological buffer.

Equilibration of a culture medium to maintain a constant $\mathrm{pH}$ under room atmosphere can be performed in a 24-well culture plate. Each well is filled with $1 \mathrm{ml}$ of the selected culture medium. Then an increasing concentration from 10 to $50 \mathrm{mmol} / \mathrm{l}$ HEPES (Nr. 15630-056, Gibco/Invitrogen) and/or 0.1 to $1.5 \%$ Bufferall (Nr. B-8405, Sigma-Aldrich Chemie) is added to each of the wells. For the following 24 hours the culture plate is incubated on a thermo plate at $37^{\circ} \mathrm{C}$ under room atmosphere. After equilibration the $\mathrm{pH}$ in each well is measured with a $\mathrm{pH}$ meter or with a whole blood analyzer such as the Stat Profile 9 Plus (Nova Biomedical, Rödermark, Germany). In that way the HEPES respectively Bufferall concentration, which yields a medium $\mathrm{pH}$ between 7.2 and 7.4 under room atmosphere, can easily be determined. Determination of the $\mathrm{pH}$ just by observation of the phenol red indicator is not recommended, since phenol red is not sensitive enough to indicate small $\mathrm{pH}$ shifts around the physiological range between $\mathrm{pH} 7.2$ and 7.4.

\section{Content of Respiratory Gas}

Epithelial tissues have highly individual oxygen requirements [72]. For that reason it is important to individually adjust the respiratory gas content in perfusion cultures. Oxygenation in gradient perfusion culture is obtained by transporting media through $1 \mathrm{~m}$ long highly gas-permeable silicone tubes with $1 \mathrm{~mm}$ inner and $3 \mathrm{~mm}$ outer diameter to al- low optimal exchange of gases. The tubing is highly gaspermeable and guarantees optimal diffusion between culture medium and surrounding room atmosphere.

\section{Metabolic Parameters}

To allow continuous control of the fluid environment throughout an experiment, medium for analysis is aspired with a sterile syringe through a $\mathrm{T}$-connection in the tube directly before or after the gradient perfusion culture container. Since the epithelia are exposed to a luminal and basal fluid environment, specimens of media are collected additionally from the luminal as well as the basal medium [73] (Table 1).

\section{TRANSPORT OF MEDIUM}

Epithelia within a gradient perfusion culture container have to be supplied with a continuous flow of fresh, oxygenated culture medium in order to obtain constant nutrition and to avoid unstirred fluid layers achieving a high degree of histotypical differentiation.

\section{Uni-Directional Transport}

Transport of culture medium is best accomplished using a slowly rotating peristaltic pump designed to deliver very low adjustable and parallel pump rates (Fig. 5). For example, it is favorable for the development of epithelia to transport medium at a rate of $1 \mathrm{ml} / \mathrm{h}$ for a 2 week culture period using an IPC N8 peristaltic pump (ISMATEC, Wertheim, Germany). In this scenario fresh culture medium is continuously supplied from a storage bottle to the gradient container. The metabolized medium is collected in a separate waste bottle and consequently not re-circulated. This guarantees on the one hand a constant nutrition and oxygen supply, while on the other hand a continuous elimination of harmful metabolic products is obtained.

Medium transport is normally started by drawing the medium up from the bottom of a storage bottle through tubes connected with the inside of the bottle cap. The suction force of the pump has to be high enough in order to overcome the difference in elevation of medium within the storage bottle 
Table 1. Physiological Parameters in Gradient Perfusion Culture Including a Sealing Epithelium on the Luminal and Basal Side in the Afferent and Efferent Tubes. During Culture the Epithelium is Exposed to a Gradient with a $\mathrm{Na}^{+}-\mathrm{Load}_{\text {at }}$ the Luminal Side (130 Versus $117 \mathrm{mmol} / \mathrm{l} \mathrm{Na}{ }^{+}$)

\begin{tabular}{|c|c|c|c|c|c|}
\hline \multicolumn{4}{|c|}{ Parameters } & \multirow{2}{*}{ Afferent } & \multirow{2}{*}{$\begin{array}{c}\text { Efferent } \\
129.7\end{array}$} \\
\hline Luminal & $\mathrm{IMDM}+\mathrm{NaCl}$ & $\mathrm{Na}^{+}$ & $\mathrm{mmol} / \mathrm{l}$ & & \\
\hline & & $\mathrm{Cl}^{-}$ & $\mathrm{mmol} / \mathrm{l}$ & 91.5 & 91.0 \\
\hline & & $\mathrm{Ca}^{++}$ & $\mathrm{mmol} / \mathrm{l}$ & 1.1 & 1.1 \\
\hline & & $\mathrm{pH}$ & & 7.4 & 7.4 \\
\hline & & $\mathrm{pO}_{2}$ & $\mathrm{mmHg}$ & 193.7 & 191.6 \\
\hline & & $\mathrm{pCO}_{2}$ & $\mathrm{mmHg}$ & 10.7 & 6.2 \\
\hline & & Glucose & $\mathrm{mg} / \mathrm{dl}$ & 443 & 443 \\
\hline \multirow{7}{*}{ Basal } & & $\mathrm{K}^{+}$ & $\mathrm{mmol} / \mathrm{l}$ & 3.9 & 3.9 \\
\hline & & $\mathrm{Cl}^{-}$ & $\mathrm{mmol} / \mathrm{l}$ & 79.8 & 80.4 \\
\hline & & $\mathrm{Ca}^{++}$ & $\mathrm{mmol} / \mathrm{l}$ & 1.1 & 1.1 \\
\hline & & Osmolarity & mOsm & 253 & 253 \\
\hline & & $\mathrm{pH}$ & & 7.4 & 7.4 \\
\hline & & $\mathrm{pO}_{2}$ & $\mathrm{mmHg}$ & 191.8 & 191.6 \\
\hline & & $\mathrm{pCO}_{2}$ & $\mathrm{mmHg}$ & 11.9 & 6.5 \\
\hline
\end{tabular}

and the capillary forces resulting from thin silicone tubes. This high negative pressure in combination with low pump rates of $1 \mathrm{ml} / \mathrm{h}$ parallels frequently with increased diffusion of gas through the tube wall, which in turn causes arise of numerous gas bubbles within the medium. The technical need is to transport oxygen-rich media by avoiding formation of gas bubbles. For this purpose special bottle caps and tubes were designed, which facilitate the transport of medium from the storage bottles to the gradient container $[67,74]$. One small opening in the cap allows a continuous piece of silicone tube to pass through avoiding material transitions along the fluid path (Fig. 6a,b). This method considerably reduces gas bubble formation. Another small opening in the screw cap holds a sterile filter allowing gas to enter the storage bottle as medium is drawn from it.

\section{Elimination of Gas Bubbles in Afferent Tubes}

The transport of medium in parallel tubes is influenced by tube material, individually capillary forces in the fluid path, hydrostatic pressure, material transitions and randomly occurring gas bubbles. During the experiments it is observed that these rheological influences are not identical in both of the parallel transporting tubes. For that reason pressure differences arise between the luminal and basal compartment of the gradient perfusion culture container during transport of medium. If this pressure difference is not compensated, this can lead to a loss of the functional seal caused by mechanical damage of the epithelial barrier.

It is frequently observed that during transport of medium gas bubbles arise in the lumen of afferent tubes connected with the gradient container. Over time the bubbles increase in size, they can leave the site of primary accumulation and then concentrate unpredictably within the afferent tubes, inside the gradient culture container but also in the efferent tubes.

Consequently, gas bubbles have to be eliminated first before reaching the gradient container. For this special purpose a gas expander module was constructed, which is linked in front of the gradient container (Fig. 6c,d). The culture medium has to cross a barrier leading to a separation of gas bubbles from the liquid phase. During this process gas bubbles are eliminated while the content of solved oxygen within the transported medium remains unaffected [75].

Moreover, the gas expander module can act as an absorber for pressure differences between the luminal and basal compartment of the gradient perfusion culture container. It is 

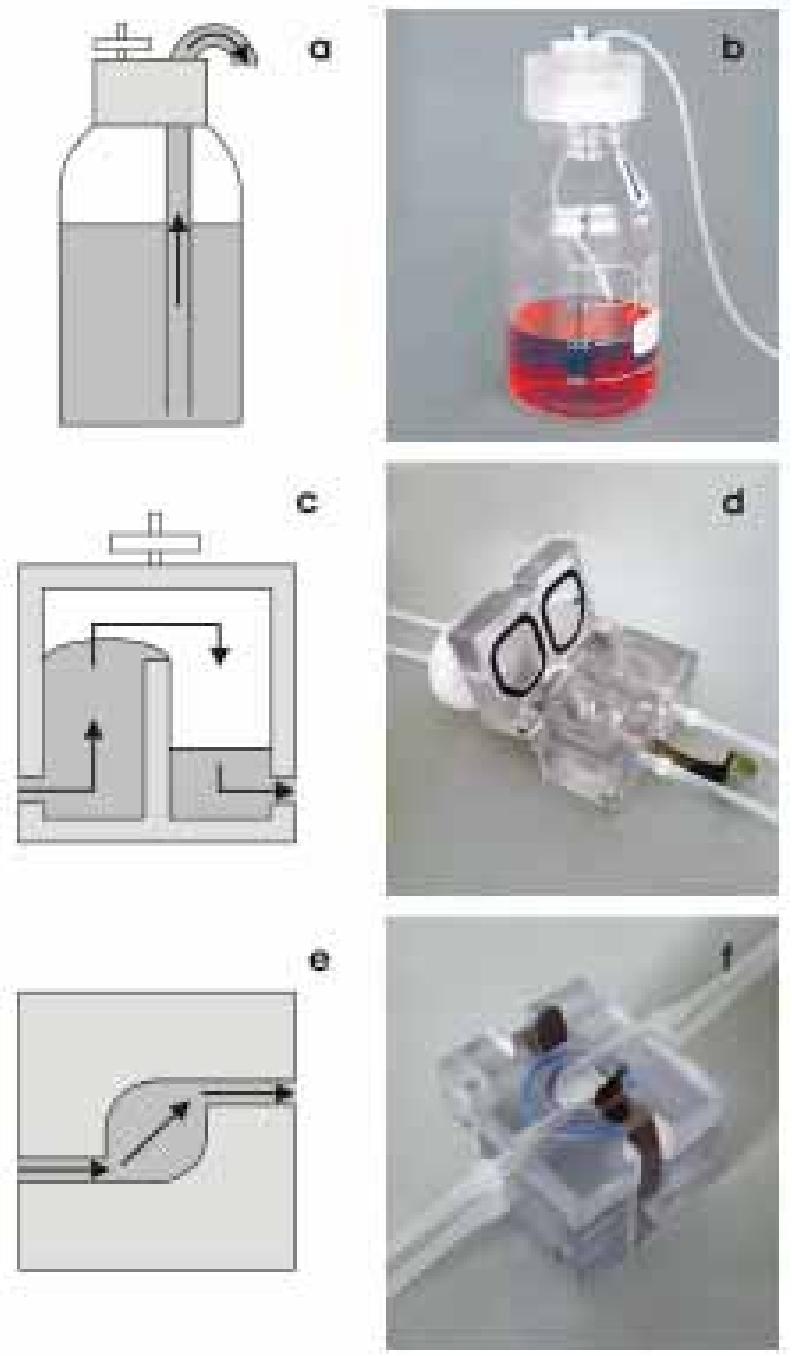

Fig. (6). Schematic and photographic images of advanced technical equipment for gradient perfusion culture. (a, b) Illustration of newly developed closures for media bottles to minimize the formation of gas bubbles. A continuous piece of silicone tubing is conducted through the closure to allow medium transport without connectors. (c, d) Lateral view to the gas expander module. Gas saturated medium enters at the one side of the module, then the medium crosses a barrier allowing gas bubbles to separate and collect in the upper half of the container. (e, f) Redesigned gradient perfusion culture container. Medium inlet and outlet are located at the tangential aspects of each tissue carrier. When the gradient container is turned to the lateral side, medium enters at the lowest point (left side), while the outlet (right side) is found at the highest point of the fluid reservoir leading to a continuous and efficient elimination of gas bubbles.

constructed as a parallel and bicameral module. Each chamber of the module is ventilated through a port at the top. This port can be used for bridging the gas phase of both chambers. This again results in identical pressures of liquid in the tubes before reaching the gradient container.

\section{Avoiding Bubbles Inside the Gradient Container}

To avoid the accumulation of gas bubbles to a critical size within the gradient container the technical contribution is to locate the medium inlet and outlet to the tangential as- pects of the tissue carrier [76] (Fig. 6e,f). Then the gradient container is turned from its base to its lateral side. Medium enters now at the lowest point, while the outlet is located at the highest point of the fluid compartment facilitating the outflow of gas bubbles. Due to this improved flow geometry gas bubbles cannot accumulate but are continuously eliminated during medium transport. Thus, the combination of newly constructed bottle caps including special tubes, a gas expander module and the redesigned gradient perfusion culture container leads to a drastic reduction of gas bubbles throughout the culture period, which in turn increases the harvest of intact epithelia.

\section{SEAL PILOTS EFFERENT FLOW}

In gradient perfusion culture epithelia have to be provided in parallel at the luminal and basal side with medium. During a long term culture period of 14 days the epithelia
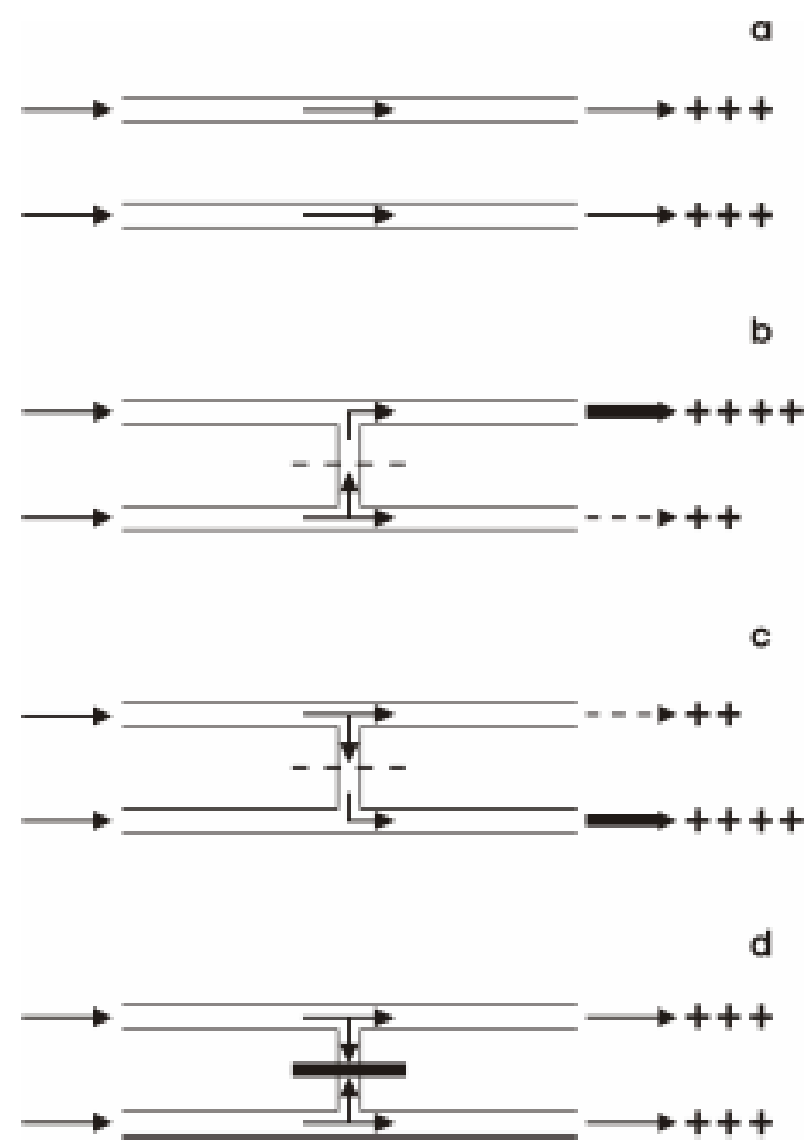

Fig. (7). The flow of medium inside a gradient perfusion culture container is directed by the epithelial seal. To ensure equal transport rates of medium parallel channels of a peristaltic pump are used. (a) This is simply to perform, when two separate channels including two separate tubes for transport of medium are used. (b, c) An identical transport rate of medium is not any more achieved when the parallel tubes are bridged by a gradient container including a non-sealing epithelium. Mixing of both media occurs inside the gradient container. The degree of mixed medium cannot be predicted, which in turn leads to an unequal transport of medium either to the one (b) or to the other (c) waste bottles. (d) Parallel transport of medium is only obtained when both tubes are bridged by a gradient culture container including a completely sealing epithelium. 
must withstand the resulting rheological forces and have to maintain a physiological barrier between the luminal and basal compartment in the gradient container as it is known from the organ site where they were derived [77].

To ensure equal transport rates of medium parallel channels of a peristaltic pump are used. Principally this is simply to perform, when two separate channels including two separate tubes for transport of medium are used (Fig. 7a). However, an identical transport rate of medium is not any more achieved when the parallel tubes are bridged by a gradient container including a non-sealing epithelium (Fig. 7b,c). In this case a mixing of both media occurs inside the gradient container. Experimental reality shows that the degree of mixed medium cannot be predicted, which in turn leads to an unequal transport of medium either to the one (Fig. 7b) or to the other (Fig. 7c) waste bottle. In consequence, parallel transport of medium is only obtained when both tubes are bridged by a gradient culture container including a completely sealing epithelium (Fig. 7d).

When a tissue carrier with a growing epithelium is inserted in the gradient container crude handling has to be avoided. It may produce mechanically micro-injuries in the cell layer, which results in leakage of the barrier. Most important, the seal is made not only by the epithelium but in close cooperation with a selected support including the tissue carrier. For that reason different kinds of leakage occur. For example, edge damage can be found at sites, where epithelial cells, support and polymer material of the tissue carrier do not stay in close contact (Fig. 8a). An epithelial leak may appear when the cultured cells do not grow to perfect confluence on the support or do not develop complete sealing between neighboring cells due to cell biological reasons (Fig. 8b). Damage may also occur due to pressure differences lifting one of the waste bottles higher than the other. Only a careful mounting of the tissue carrier, a slow transport of medium and a perfect growth of cells in combination keeps the gradient container separated in a luminal and basal compartment, so that mixing of the two media does not occur (Fig. 8c).

\section{EMBOLIC OBSTRUCTION IN EFFERENT TUBES}

The crucial technical problem in gradient perfusion culture is that the epithelial cells grow on a support, which vibrates between the luminal and basal compartment depending on the environmental pressure to a more or less extent. As long as the epithelia are kept on mechanically rigid support materials such as nitrocellulose or polycarbonate filters, the transport of media will not severely affect the barrier function since a certain mechanical stability is given by compensating the pressure difference to a certain degree. However, in multiple cases epithelia are kept on mechanically more fragile collagen supports. These can only be well preserved in the gradient container as long as pressure differences between the luminal and basal compartment are minimized.

Pressure differences do not only arise in afferent tubes, but also in efferent tubes. They can be caused by lifting only one of the waste bottles, but also by embolic obstruction. During experimental run gas bubbles can be imported, but they do also arise due to the respiratory activity of the cultured epithelia within a gradient container. During a long
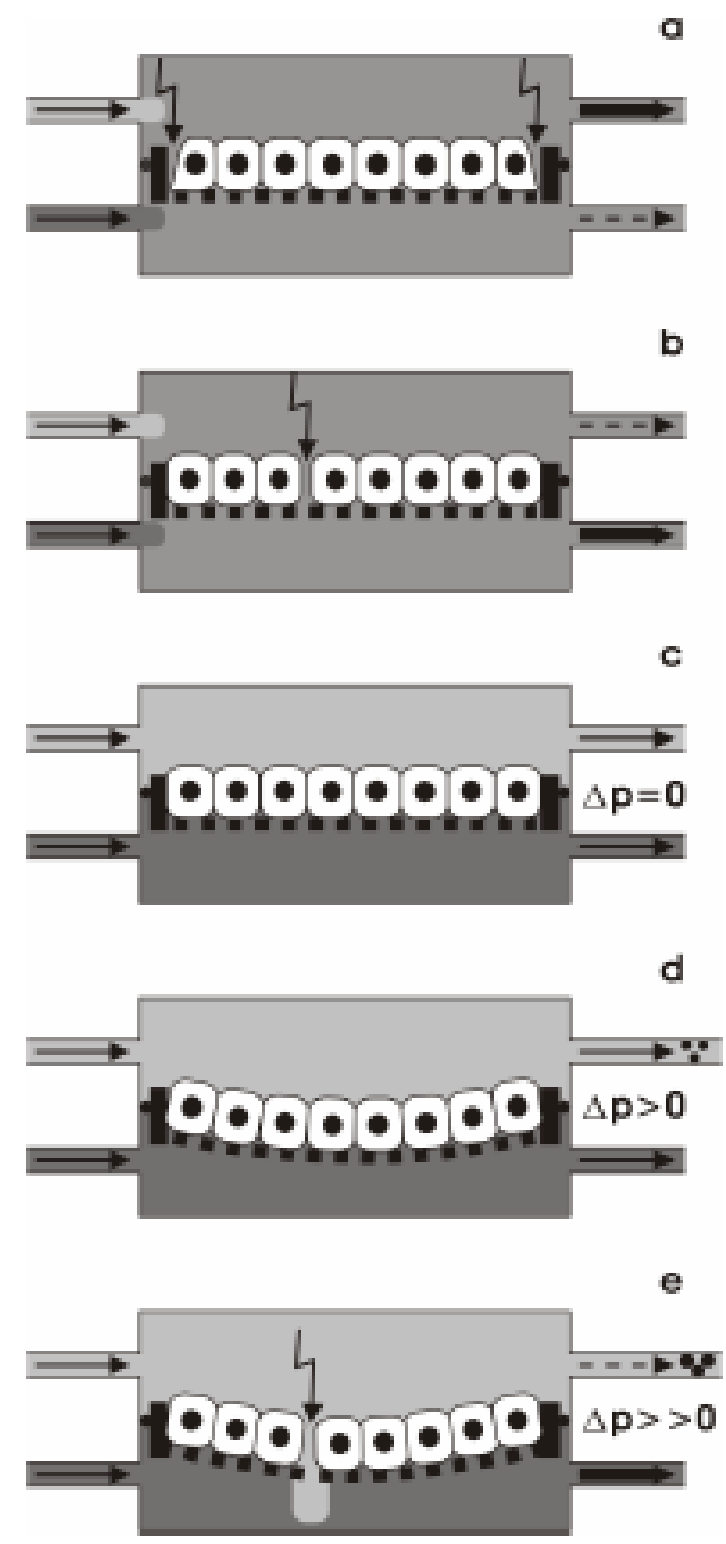

Fig. (8). Schematic illustration of epithelial damage during run of gradient perfusion culture. (a, b) Leakage in the seal may occur by edge damage (a) or lack of confluence (b). (c) For a functional barrier it is essential that the growing epithelium produces a perfect seal together with the support and the tissue carrier. No epithelial tissue damage will occur as long as pressure is identical at the luminal and basal side of the gradient culture container $(\Delta p=0)$. (d) However, small gas bubbles (small black dot), for example in the luminal efferent tube, will increase the pressure in the luminal compartment resulting in an extension of the epithelium towards the basal side $(\Delta \mathrm{p}>0)$. (e) As gas bubble grow in diameter (bigger black dot) a further pressure increase in the luminal compartment occurs $(\Delta \mathrm{p}>>0)$ so that the epithelium disrupts during run of the experiment.

term culture period they increase in diameter. Part of them is leaving the gradient container towards an efferent tube. This in turn leads to obstruction of the medium outflow. However, perfect culture in a gradient container only occurs in the absence of a pressure difference between the luminal and basal compartment (Fig. 8c; $\Delta \mathrm{p}=0$ ). As the obstruction ran- 
domly affects only the basal or the apical medium transport the resulting pressure difference causes a protrusion of the epithelium towards the side of lower pressure (Fig. 8d; $\Delta \mathrm{p}>$ $0)$. An increasing pressure difference will finally result in the mechanical disruption of the epithelial barrier (Fig. 8e; $\Delta \mathrm{p}>$ $>0)$.

\section{MONITORING THE EPITHELIAL BARRIER}

After the careful insertion of a tissue carrier into a gradient perfusion culture container both the apical and the basal side of the epithelium can be provided with media. Depending on the state of development identical or individual medium composition is offered. If an immature epithelium is inserted a sealing barrier between the luminal and basal compartment is not established yet. Consequently, an uncontrolled exchange of fluid between the luminal and basal compartment of the epithelium may occur until the epithelium has matured during ongoing culture.

Electrophysiological registration of trans-epithelial potential difference and resistance over 14 days in a continuous process proved less suitable to control the development and maintenance of a sealing barrier during long term gradient perfusion culture experiments. Electrode fouling, resulting tissue damage and a decreased degree of cellular differentiation were observed. Addition of radiolabeled molecules to the luminal culture medium in combination with detection of radioactivity in the basal medium path seems possible. However, this is not preferred since non-radioactive fluorescent molecules can be employed better to monitor the quality of the epithelial barrier throughout a long term gradient perfusion culture period.

A simple and cost saving method to detect nonphysiological epithelial leaks is to transport IMDM containing phenol red (order \# 21980 - 032; Gibco/Invitrogen) at the luminal compartment, while IMDM without phenol red (order \# 21056 - 023; Gibco/Invitrogen) is provided at the basal side of the gradient container. Photometrically recorded traces of phenol red indicator in the clear medium indicate mixing of both media and demonstrate the leakage of the epithelium. Only experiments with a perfect parallel transport of red and clear media in the waste bottles indicate a successful barrier function.

A further way of detecting epithelial leakage is to collect medium samples just before and after the luminal and basal compartment of the gradient perfusion container and to analyze these samples in a blood electrolyte analyzer (Table 1). As the media used in the luminal and basal fluid path differ in their electrolyte composition, the stability of the fluid gradient can be controlled over days. In this case the concentrations of key electrolytes (e.g. $\mathrm{Na}$ or $\mathrm{Cl}$ ) or osmolarity in medium are compared as well in afferent and efferent tubes at the luminal and basal compartment of the gradient perfusion culture container $[64,65,73]$.

\section{HARVESTING DIFFERENTIATED EPITHELIA}

A parallel transport of medium during experimental run shows that an intact barrier is established. The biological seal is produced by the epithelial cells during gradient perfusion culture. This development is a rather complex cell biological process starting with the formation of cell-cell-contacts, followed by the intense adhesion to the extracellular matrix and the definition of polarization [44]. A complex concert of further influences such as paracrine factors, growth factors, hormones, nutrition, respiratory gas, metabolites and biophysical stress such as hydrostatic pressure or fluid osmolarity stimulates the development from an immature state towards a physiological epithelial barrier (Fig. 1). As a consequence, the junction belt between the luminal and lateral plasma membrane is functionally closed so that the paracellular shunt is controlled [77]. From this point of development onward exclusively the epithelial cells control, which electrolytes or other molecules are allowed to pass the barrier. Once the development is finished, the luminal and basal fluid environments are completely separated by the epithelium during gradient perfusion culture. Under these conditions the development of embryonic cells towards a matured renal collecting duct epithelium was investigated [62,64$67,75,78-82]$. During a culture period of 14 days the epithelium was provided with $1 \mathrm{ml} / \mathrm{h}$ on the basal side with IMDM, while on the luminal side IMDM $+12 \mathrm{mmol} / \mathrm{l} \mathrm{NaCl}$ was transported. Immuno-histochemistry demonstrates that a polarized collecting duct epithelium with a nephron-specific differentiation profile is harvested (Fig. 9). The occurrence of laminin $\gamma 1$ for example shows, that the epithelium rests on a newly synthesized basal lamina (Fig. 9a). The upregulation of cingulin reveals the formation of a tight junctional complex between the luminal and lateral plasma membrane (Fig. 9b), while the label for $\mathrm{Na} / \mathrm{K}$-ATPase (Fig. 9c), aquaporin (AQP 3, Fig. 9d) and Cox 2 (Fig. 9e) demonstrates the presence of typical functional features. Finally, occurrence of cytokeratin 19 (Fig. 9f), cytokeratin EndoA (Fig. 9g) and e-cadherin (Fig. 9h) exhibits further nephronspecific characteristics.

\section{APPLICATIONS OF GRADIENT PERFUSION CUL- TURE}

Up to date more than 180 reviewed papers including patents could be found dealing with Minusheet ${ }^{\circledR}$ perfusion culture technology. Among them over 40 are reviewed papers using Minusheet ${ }^{\circledR}$ gradient perfusion culture technique. Related literature is listed: www.biologie.uni-regensburg.de/ Anatomie/Minuth/proceedings.htm.

\section{Renal Collecting Duct Epithelium}

Experiments with gradient perfusion culture were started years ago in our laboratory to investigate the maturation of an embryonic collecting duct epithelium derived from renal stem/progenitor cells [62,64-67,75,78,79,80-82]. In this coherence it was found that differentiation of a renal epithelium takes an unexpected long period of 14 days and is dependent on the electrolyte composition offered at the luminal and basal side. Only in an electrolyte gradient specific features such as binding for PNA-lectin or binding of monoclonal antibodies 503 and 703 - all of them specifically reacting on renal collecting duct cells - were found to be upregulated. Applying gradient perfusion culture it became for the first time possible to investigate the maturation of an embryonic epithelium under realistic conditions as found during development within an organ.

\section{Ophalmology}

Successful perfusion culture in a gradient container was performed with retina $[69,83-88]$. In contrast to static culture 

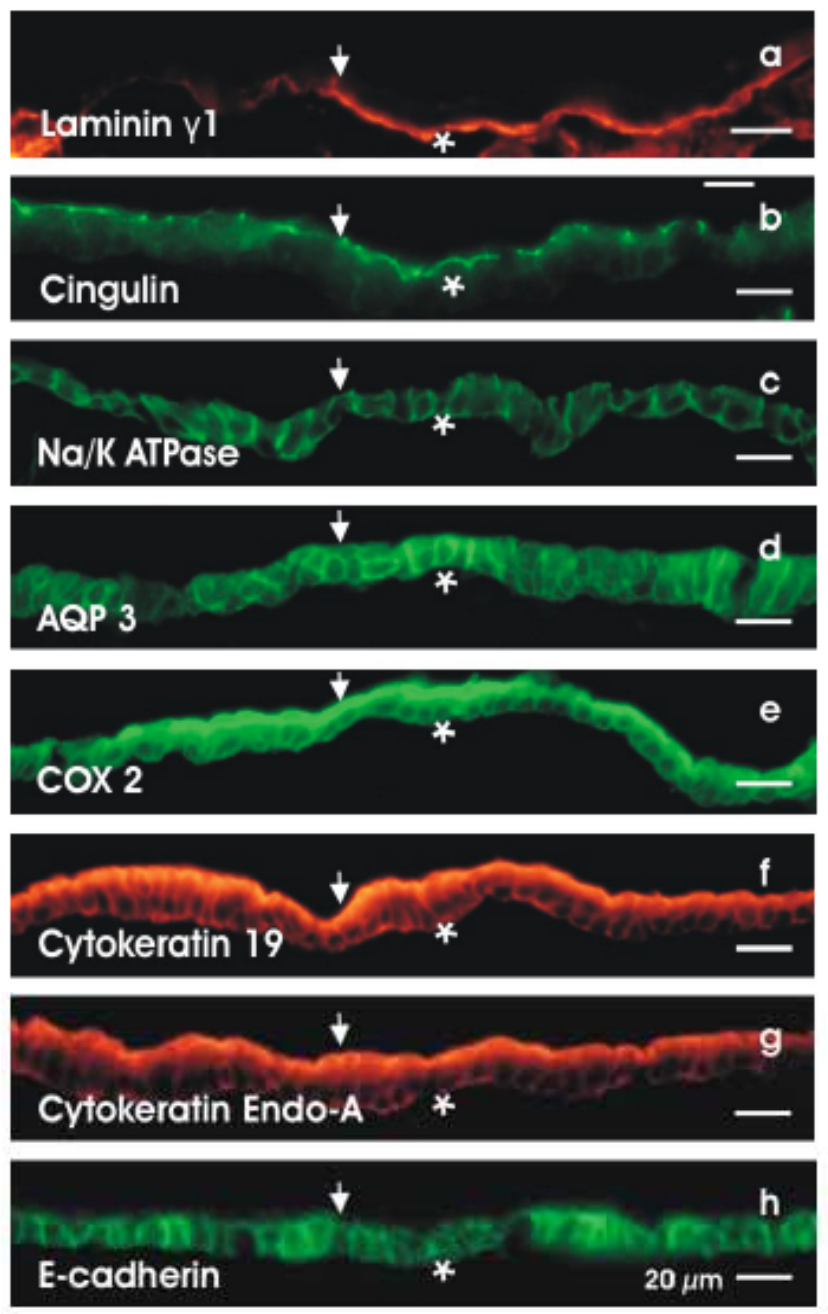

Fig. (9). Immunohistochemistry on cryosections of an epithelium kept for 14 days in gradient perfusion culture with IMDM on the basal side and IMDM $+12 \mathrm{mmol} / \mathrm{l}$ at the luminal side. (a) Antilaminin $\gamma 1$ shows, that the epithelium rests on a newly synthesized basal lamina. (b-e) Positive reaction with anti-cingulin reveals the formation of a junctional complex between the luminal and lateral plasma membrane (b), while the label for $\mathrm{Na} / \mathrm{K}$-ATPase (c), aquaporin 3 (AQP 3, (d) and Cox 2 (e) demonstrates the presence of cell-specific functional features. (f-h) Expression of cytokeratin 19 (f) and cytokeratin EndoA (g) and e-cadherin (h) presents nephronspecific antigens. Basal lamina — asterisk; lumen — arrow.

it could be shown, for example, that neurons and retinal pigment epithelium maintains a perfect morphology for at least 10 days. This opens new perspectives for safety testing of pharmaceuticals designed for intraocular application. The new approach opens now the possibility to investigate in vitro the wide field of related regeneration.

\section{Blood-Retina and Blood-Brain Barrier Tests}

For pharmaceutical studies experiments with blood-retina and blood-brain barrier were performed in gradient perfusion culture to investigate drug permeation by different methods $[89,90]$. The permeation characteristics displayed an intact polarized expression of efflux pumps such as multidrug resistance protein $(\mathrm{P}-\mathrm{gp})$ and multidrug resistance-associated protein (MRP).

\section{Blood-Air Barrier}

Investigations on lung were performed with gradient perfusion culture [91-94]. In those experiments cellular interactions and the alveolar metabolism were investigated. When pneumocytes and endothelial cells were co-cultured on a polycarbonate filter within a gradient perfusion container characteristic morphological features were developed and tight junctions were sealing the blood-air barrier. It was concluded that gradient perfusion culture in combination with pneumocytes and endothelial cells is a promising realistic model to investigate dose-controlled exposure of airborne particles, features of barrier transport and repair mechanisms after alveolar injury.

\section{Blood-Gas Barrier}

Experiments on fish swim bladder gas gland was successfully performed with gradient perfusion culture [95]. Cells of gas gland were cultured at the interface between gas and medium. The epithelium revealed a typical polarity and functionality as observed in the in vivo situation.

\section{Pharmaceutical Application}

Pharmaceuticals were applied in gradient perfusion culture [71, 96-98]. It was found for example that the gradient perfusion culture with Caco- 2 cells generated sealing epithelia and revealed reproducible results much earlier than traditional 21-day static cultures. In addition, the permeability coefficient of several model compounds across Caco-2 cells was in gradient perfusion culture approximately twofold higher than obtained with static conditions.

\section{Regenerating Vessels}

Development on micro-vessels was made by gradient perfusion culture $[99,100]$. In these experiments capillarylike structures were found in the luminal portion of perfused vessel equivalents. It is shown that pulsatile perfusion promotes better the development of a capillary-like network than continuous transport of medium.

\section{Reparing Epidermis}

Epidermis equivalents were generated with gradient perfusion culture [101]. Composite grafts of INTEGRA ${ }^{\circledR}$ matrix and human keratinocytes were cultured in a gradient container in order to evaluate the potential for the cost-effective engineering of full-thickness skin grafts and the treatment of ulcers.

\section{Non-Epithelial Barrier}

Experiments related to non-epithelial biomaterial testing were performed with dentin discs in gradient perfusion culture [102-109]. Polymerized dental resin materials release residual monomers that may interact with pulp tissue. This modified dentin barrier test reveals as an ideal model to investigate described effects. New insights in permeability testing of gelatine membranes were obtained by using fibroblasts in a gradient container [110].

\section{Over-View}

Finally, basic information due to Minusheet ${ }^{\circledR}$ gradient perfusion culture technique was earlier described $[63,75]$. 
The increasing applications made it necessary to write this article focussing to actual applications.

\section{CONCLUSIONS}

During the last years a versatile modular system for the generation of epithelia within a gradient perfusion culture container was elaborated. With respect to the numerous factors that influence epithelial development the culture system was designed to allow individual control of a number of important environmental parameters. That way the microenvironment within the gradient perfusion culture container can be fine-tuned to meet the physiological needs of numerous types of epithelia. An innovative construction principle allows the application of gradient perfusion culture at minimal financial expenditure and the individual modules can be combined as needed to build a number of advanced customized culture set-ups. Thus, a variety of epithelia can be kept under tissue-specific conditions to study adherence on new biomaterials, cellular communication, epithelial development and effects of newly developed pharmaceuticals.

\section{ACKNOWLEDGEMENTS}

The skillful technical assistance of Mr. Anthonie Maurer is gratefully acknowledged.

Technical information: Minucells and Minutissue GmbH, D-93077 Bad Abbach, Germany, www. minucells.de. Scientific information: Will W. Minuth, Molecular and Cellular Anatomy, University of Regensburg, Universitätstrasse 31, D - 93053 Regensburg, Germany; Tel: +49 (0) 941943 2876; Fax: +49 (0) 941943 2868; E-mail: will.minuth@vkl.uni-regensburg.de

\section{REFERENCES}

[1] Ojeh NO, Frame JD, Navsaria HA. In vitro characterization of an artifical dermal scaffold. Tissue Eng 2001; 7(4): 457-72.

[2] Jahoda CA, Reynolds AJ. Hair follicle dermal sheath cells: unsung participants in wound healing. Lancet 2001; 358(9291): 1445-8.

[3] Gusic RJ, Myung R, Petko M, Gaynor JW, Gooch KJ. Shear stress and pressure modulate saphenous vein remodeling ex vivo. $\mathrm{J}$ Biomech 2005 ; 38(9): 1760-9.

[4] Brown RA, Philips JB. Cell responses to bimimetic protein scaffolds used in tissue repair and engineering. Int Rev Cytol 2007; 262: 75-150.

[5] Metcalfe AD, Ferguson MW. Skin stem and progenitor cells: using regeneration as a tissue engineering strategy. Cell Mol Life Sci 2008; 65(1): 24-32.

[6] Nerem RM, Seliktar D. Vascular tissue engineering. Annu Rev Biomed Eng 2001; 3: 225-43.

[7] Jockenhoevel S, Zund G, Hoerstrup SP, Schnell A, Turina M. Cardiovascular tissue engineering: a new laminar flow chamber for in vitro improvement of mechanical tissue properties. ASAIO J 2002; 48(1): 8-11.

[8] Le Brocq M, Leslie SJ, Milliken P, Megson IL. Endothelial dysfunction: from molecular mechanisms to measurement, clinical implications, and therapeutic opportunities. Antoxid Redox Signal 2008; 10(9): 1631-74.

[9] Kawamoto A, Losordo DW. Endothelial precursor cells for cardiovascular regeneration. Trends Cardiovasc Med 2008; 18(1): 33-7.

[10] Vacanti JP, Langer R. Tissue engineering: the design and fabrication of living replacement devices for surgical reconstruction and transplantation. Lancet 1999; 354(1): SI32-4.

[11] Langer RS, Vacanti JP. Tissue engineering: the challenges ahead. Sci Am 1999; 280(4): 86-9.

[12] Gerlach JC, Zeilinger K, Patzer JF. Bioartificial liver systems: why, what, whither? Regen Med 2008; 3(4): 575-95.

[13] Lysy PA, Campard D, Smets F, Najimi M, Sokal EM. Stem cells for liver tissue repair: current knowledge and perspectives. World J Gastroenterol 2008; 14(6): 864-75.
[14] Donato MT, Lahoz A, Castell JV, Gomez-Lechon MJ. Cell lines: a tool for in vitro drug metabolism studies. Curr Drug Metab 2008; 9(1): 1-11.

[15] Hollande E, Cantet S, Ratovo G, Daste G, Bremont F, Fanjul M. Growth of putative progenitors of type II pneumocytes in culture of human cystic fibrosis alveoli. Biol Cell 2004; 96(6): 429-41.

[16] Van Vranken BE, Rippon HJ, Samadikuchaksaraei A, Trounson AO, Bishop AE. The differentiation of distal lung epithelium from embryonic stem cells. Curr Protoc Stem Cell Biol 2007; 1: Unit $1 \mathrm{G} 1$

[17] Sporty JL, Horalkova L, Ehrhardt C. In vitro cell culture models for the assessments of pulmonary drug disposition. Expert Opin Drug Metab Toxicol 2008; 4(4): 333-45.

[18] Humes HD. Bioartificial kidney for full renal replacement therapy. Semin Nephrol 2000; 20(1): 71-82.

[19] Pariente JL, Bordenave L, Bareille R, Baquey C, Le Guillou M. Cultured differentiated human urothelial cells in the biomaterials field. Biomaterials 2000; 21(8): 835-9.

[20] Crallan RA, Georgopoulos NT, Southgate J. Experimental models of human bladder carcinogenesis. Carcinogenesis 2006; 27(3): 374 81.

[21] Eblin KE, Bredfeldt TG, Gandolfi AJ. Immortalized human urothelial cells as a model of arsenic-induced bladder cancer. Toxicology 2008; 248(2-3): 67-76.

[22] Hayashi K, Ando N, Ozawa S, et al. A neo-esophagus reconstructed by cultured human esophageal epithelial cells, smooth mucle cells, fibroblasts, and collagen. ASAIO J 2004; 50(3): 261-6.

[23] Kavvada KM, Murray JG, Moore VA, Coombes AG, Hanson PJ. A collagen IV matrix is required for guinea pig gastric epithelial cell monolayers to provide an optimal model of the stomach surface for biopharmaceutical screening. J Biomol Screen 2005; 10(5): 495507.

[24] Croagh D, Chen S, Tikoo A, et al. Reconstitution of stratified murine and human oesophageal epithelia in an in vivo transplant culture system. Scand J Gastroenterol 2008; 43(10): 1158-68.

[25] Kong J, Nalagawa H, Isaryawongse B, et al. Induction of internalization in human oesophageal keratinocytes is a multi-step process. Carcinogenesis 2009; 30(1): 122-30.

[26] Ziegelaar BW, Aigner J, Staudenmaier R, et al. The characterisation of human respiratory epithelial cells cultured on resorbable scaffolds: first steps towards a tissue engineered tracheal replacement. Biomaterials 2002; 23(6): 1425-38.

[27] Kojima K, Vacanti CA. Generation of a tissue-engineered tracheal equivalent. Biotechnol Appl Biochem 2004; 39(3): 257-62.

[28] Widdicombe JH, Sachs LA, Morrow JL, Finkbeiner WE. Expansion of cultures of human tracheal epithelium with maintenance of differentiated structure and function. Biotechniques 2005; 39(2): 249-55.

[29] Shibeshi W, Abranham G, Kneuer C, et al. Isolation and culture of primary equine tracheal epithelial cells. In Vitro Cell Dev Biol Anim 2008; 44(7): 179-84.

[30] Stennert E, Siefer O, Zheng M, Walger M, Mickenhagen A. In vitro culturing of porcine tracheal mucosa as an ideal model for investigating the influence of drugs on human respiratory mucosa. Eur J Arch Otolaryngol 2008; 265(9): 1075-81.

[31] Rothen-Rutishauser B, Mueller L, Blank F, Brandenberger C, Muelfeld C, Gehr P. A newly developed in vitro model of the human epithelial airway barrier to study the toxic potential of nanoparticles. ALTEX 2008; 25(3): 1991-6.

[32] Bhadriraju K, Hansen LK. Hepatocyte adhesion, growth and differentiated function on RGD-containing proteins. Biomaterials 2000; 21(3): 267-72.

[33] Bianco P, Robey PG. Stem cells in tissue engineering. Nature 2001; 414(6859): 118-21.

[34] Pilot F, Lecuit T. Compartimentalized morphogenesis in epithelia: from cell to tissue shape. Dev Dyn 2005; 232(3): 685-694.

[35] Kilgour JD, Simpson SA, Alexander DJ, Reed CJ. A rat nasal epithelial model for predicting upper respiratory tract toxicity: in vivo-in vitro correlations. Toxicology 2000; 154(1): 39-45.

[36] Vogt F, Stein A, Rettemeier G, et al. Long-term assessment of a novel biodegradable paclitaxel-eluting coronary polylactide stent. Eur Heart J 2004; 25(15): 1330-40.

[37] Evans MD, McFarland GA, Taylor S, Walboomers XF. The response of healing corneal epithelium to grooved polymer surfaces. Biomaterials 2005; 26(14): 1703-11. 
[38] Pins GD, Toner M, Morgan JR. Microfabrication of an analog of the basal lamina: biocompatible membranes with complex topographies. FASEB J 2000; 14(3): 593-602.

[39] Korah R, Das K, Lindy ME, Hameed M, Wieder R. Coordinate loss of fibroblast growth factor 2 and laminin 5 expression during neoplastic progression of mammary duct epithelium. Hum Pathol 2007; 38(1): 154-60.

[40] Prasad CK, Muraleedharan CV, Krishnan LK. Bio-mimetic composite matrix that promotes endothelial cell growth for modification of biomaterial surface. J Biomed Mater Res A 2007; 80(3): 644-54.

[41] Van Vranken BE, Romanska HM, Polak JM, Rippon HJ, Shannon JM, Bishop AE. Coculture of embryonic stem cells with pulmonary mesenchyme: a microenvironment that promotes differentiation of pulmonary epithelium. Tissue Eng 2005; 11(7-8): 1177-87.

[42] Mrsny RJ. Modification of epithelial tight junction integrity to enhance transmucosal absorption. Crit Ther Drug Carrier Syst 2005; 22(4): 331-418.

[43] Shurman DL, Glazewski L, Gumpert A, Zieske JD, Richard G. In vivo and in vitro expression of connexins in the human corneal epithelium. Invest Ophthalmol Vis Sci 2005; 46(6): 1957-65.

[44] Lacorre DA, Baekkevold ES, Garrido I, et al. Plasticity of endothelial cells: rapid dedifferentiation of freshly isolated high endothelial venule endothelial cells outside the lymphoid tissue microenvironment. Blood 2004; 103(11): 4164-72.

[45] Cho EH, Yang YI, Mun CW, Kim JK. Tissue-engineered semimicroporous segmented polyetherurethane vascular prothesis. J Biomater Sci Polym Ed 2005; 16(6): 775-90.

[46] Ferrari S, Pellegrini G, Mavilio F, De Luca M. Gene therapy approaches for epidermolysis bullosa. Clin Dermatol 2005; 23(4): 430-6.

[47] Li Y, Yang J, Luo JH, Dedhar S, Liu Y. Tubular epithelial cell dedifferentiation is driven by the helix-loop-helix transcriptional inhibitor Id1. J Am Soc Nephrol 2007; 18(2): 449-60.

[48] Flieger A, Golka K, Schulze H, Follmann W. Primary cultures of human urothelial cells for genotoxicity testing. J Toxicol Environ Helath A 2008; 71(13-14): 930-5.

[49] Terramani TT, Eton D, Bui PA, Wang Y, Weaver FA, Yu K. Human macrovascular endothelial cells: optimization of culture conditions. In Vitro Cell Dev Biol Anim 2000; 36(2): 125-32.

[50] Kurosawa H, Yuminamochi E, Yasuda R, Amano Y. Morphology and albumin secretion of adult rat hepatocytes cultured on a hydrophobic porous expanded polytetrafluorethylene membrane. J Biosci Bioeng 2003; 95(1): 59-64.

[51] Toimela T, Maenpaa H, Mannerstrom M, Tahti H. Development of an in vitro blood-brain barrier model-cytotoxicity of mercury and aluminum. Toxicol Appl Pharmacol 2004; 195(1): 73-82.

[52] Suzuki M, Mimuro H, Suzuki T, Park M, Yamamoto T, Sasakawa C. Interaction of CagA with Crk plays an important role in Helicobacter pylori-induced loss of gastric epithelial cell adhesion. I Exp Med 2005; 202(9): 1235-47.

[53] Lechler T, Fuchs E. Asymetric cell divisions promote stratification and differentiation of mammalian skin. Nature 2005; 437(70056): 275-80.

[54] Iwaguro H, Asahara T. Endothelial progenitor cell culture and gene transfer. Methods Mol Med 2005; 112: 239-47.

[55] Monga SP, Hout MS, Baum MJ, et al. Mouse fetal liver cells in artificial capillary bed in three-dimensional four-compartment bioreactors. Am J Pathol 2005; 167(5): 1279-92.

[56] Hyatt BA, Shangguan X, Shannon JM. FGF-10 induces SP-C and Bmp4 and regulates proximal-distal patterning in embryonic tracheal epithelium. Am J Physiol Lung Cell Mol Physiol 2004; 287(6): L1116-26.

[57] Poumay Y, Dupont F, Marcoux S, Leclercq-Smekens M, Herin M, Coquette A. A simple reconstructed human epidermis: preparation of the culture model and utilization in in vitro studies. Arch Dermatol Res 2004; 296(5): 203-11.

[58] Baehr C, Reichel V, Fricker G. Choroid plexus epithelial monolayers - a cell culture model from porcine brain. Cerebrospinal Fluid Res 2006; 21: 3-13.

[59] Tummers M, Yamashiro T, Thesleff I. Modulation of cell fate of the root in vitro. J Dent Res 2007; 86(11): 1063-7.

[60] Zozulya A, Weidenfeller C, Galla HJ. Pericyte-endothelial cell interaction increases MMP-9 secretion at the blood -brain barrier in vitro. Brain Res 2008; 1189: 1-11.
[61] Minuth WW, Rudolph U. A compatible support system for cell culture in biomedical research. Cytotechnology 1990; 4: 181-9.

[62] Minuth WW, inventor. Methode zur Kultivierung von Zellen. German Patent DE-PS 3923279, 1990.

[63] Minuth WW, Strehl R. Technical and theoretical considerations about gradient perfusion culture for epithelia used in tissue engineering, biomaterial testing and pharmaceutical research. Biomed Mater 2007; 2: R1-R11.

[64] Minuth WW, Aigner J, Kloth S, Steiner P, Tauc M, Jennings ML. Culture of embryonic renal collecting duct epithelia kept in a gradient container. Ped Nephrol 1997; 11: 140-7.

[65] Minuth WW, Steiner P, Strehl R, Schumacher K, de Vries U, Kloth S. Modulation of cell differentiation in perfusion culture. Exp Nephrol 1999; 7: 394-406.

[66] Minuth WW, Schumacher K, Strehl R. Renal epithelia in long term gradient culture for biomaterial testing and tissue engineering. Biomed Mater Eng 2005; 15(1-2): 51-63.

[67] Schumacher K, Strehl R, de Vries U, Minuth WW. Advanced technique for long term culture of epithelia in a continuous luminal basal medium gradient. Biomaterials 2002; 23(3): 805-15.

[68] Minuth WW, Majer V, Kloth S, Dermietzel R. Growth of MDCK cells on non-transparent supports. In vitro Cell Dev Biol Anim 1994; 30: 12-4.

[69] Framme C, Kobuch K, Eckert E, Monzer J, Roider J. RPE in perfusion tissue culture and its response to laser application. Ophthalmologica 2002; 6: 320-8.

[70] Steuer H, Jaworski A, Stoll D, Schlosshauer B. In vitro model of the outer blood-retina barrier. Brain Res Protocols 2004; 13: 26-36.

[71] Masungi C, Borremans C, Willems B, et al. Usefullness of a novel Caco-2 cell perfusion system. I. In vitro prediction of the absorption potential of passively diffused compounds. J Pharm Sci 2004; 9388(10): 2507-21.

[72] Strehl R, Schumacher K, Minuth WW. Controlled respiratory gas delivery to embryonic renal epithelial explants in perfusion culture. Tissue Eng 2004; 10(7/8): 1196-203.

[73] Minuth WW, Schumacher K, Strehl R, Kloth S. Physiological and cell biological aspects of perfusion culture technique employed to generate differentiated tissues for long term biomaterial testing and tissue engineering. J Biomater Sci Polymer Ed 2000; 11(5): 495522 .

[74] Minuth WW, inventor. Vorrichtung zum Kultivieren und/oder Differenzieren und/oder Halten von Zellen und/oder Geweben. German Patent; DE 19952847B4, 2006.

[75] Minuth WW, Strehl R, Schumacher K, deVries U. Long term culture of epithelia in a continuous fluid gradient for biomaterial testing and tissue engineering. J Biomat Sci Polym Ed 2001; 12(13): 353-65.

[76] Lorenz-Minuth K, inventor; Gradientenkammer zur Kultivierung und/oder Differenzierung von Zellen/Geweben. German Patent; 102004054125A1 pending, 2004.

[77] Stockmann M, Gitter AH, Sorgenfrei M, Fromm M, Schulzke JD. Low edge damage container insert that adjusts intestinal forceps biopsies into Ussing chamber systems. Pflügers Arch 1999; 438: 107-12.

[78] Minuth WW, Dermietzel R, Kloth S, Henerkes B. A new method culturing renal cells under permanent perfusionand producing a luminal-basal medium gradient. Kidney Int 1992; 41: 215-9.

[79] Minuth WW, Stöckl G, Kloth S, Demietzel R. Construction of an apparatus for cell and tissue cultures which enables in vitro experiments under organo-typical conditions. Eur J Cell Biol 1992; 57: 132-7.

[80] Minuth WW, Steiner P, Strehl R, Kloth S. Electrolyte environment modulated differentiation in embryonic renal collecting duct epithelium. Exp Nephrol 1997; 5: 414-22.

[81] Minuth WW, Aigner J, Kubat B, Kloth S. Improved differentiation of renal tubular epithelium in vitro Potential for tissue engineering. Exp Nephrol 1997; 5: 10-7.

[82] Steiner P, Strehl R, Kloth S, Tauc M, Minuth WW. In vitro development and preservation of specific features of collecting duct epithelial cells from embryonic rabbit kidney are regulated by the electrolyte environment. Differentiation 1997; 62: 193-202.

[83] Spiegel D, Schefthaler M, Kobuch K. Outflow facilities through Descemet's membrane in rabbits. Graef's Arch Clin Exp Ophatalmol 2002; 240: 111-3. 
[84] Saikia P, Maisch T, Kobuch K, et al. Safety testing of indocyanine Green in an ex vivo porcine retina model. Investig Ophatalmol Visual Sci 2006; 47,11: 4998-5003.

[85] Jian GE, Jingbo L. The stem cell and tissue engineering research in chinese ophalmology. Front Med China 2007; 1(1): 6-10.

[86] Hamilton RD, Foss AJ, Leach L. Establishment of a human in vitro model of the outer blood-retinal barrier. J Anat 2007; 211(6): 70716.

[87] Hammer M, Richter S, Kobuch K, Mata N, Schweitzer D. Intrinsic tissue fluorescence in an organotypic perfusion culture of the porcine ocular fundus exposed to blue light and free radicals. Graefes Arch Clin Exp Ophtalmol 2008; 246(7): 979-88.

[88] Kobuch K, Hermann WA, Framme C, Sachs HG, Gabel VP. Maintenance of adult porcine retina and retinal pigment epithelium in perfusion culture: characterization of an organotypic in vitro model. Exp Eye Res 2008; 86: 661-8.

[89] Steuer H, Jaworski A, Stoll D, Schlosshauer B. In vitro model of the outer blood-retina barrier. Brain Res Protocols 2004; 13: 26-36.

[90] Steuer H, Jaworski A, Eleger B, et al. Functional characterization and comparison of the outer blood-retina barrier and the bloodbrain barrier. Invest Ophthalmol Visual Sci 2005; 46(3): 1047-53.

[91] Gueven N, Glatthaar B, Manke HG, Haemmerle H. Co-cultivation of rat pneumocytes and bovine endothelial cells on a liquid-air interface. Eur Respir J 1996; 9: 968-75.

[92] Tippe A, Heinzmann U, Roth C. Deposition of fine and ultrafine aerosol particles during exposure at the air/cell interface. Aerosol Sci 2002; 33: 207-18.

[93] Bitterle E, Karg E, Schroeppel A, et al. Dose-controlled exposure of A549 epithelial cells at the air-liquid interphase to airborne ultrafine carbonaceous particles. Chemosphere 2006; 65(10): 178490

[94] Maier KL, Alessandrini F, Becker-Speier T, et al. Health effects of ambient particulate matter - biological mechanisms and inflammatory responses to in vitro and in vivo particle exposures. Inhal Toxicol 2008; 20(3): 319-37.

[95] Prem C, Pelster B. Swimbladder gas gland cells of the European eel cultured in superfusion system. Methods Cell Sci 2000; 22: 125-32.

[96] Masungi C, Mensch J, Willems B, et al. Usefulness of a novel Caco-2 cell perfusion system II. Characterization of monolayer properties and peptidase activity. Pharmazie 2009; 64: 36-42.

[97] Kloth S, Kobuch K, Domokos J, Wanke C, Minuth WW. Interactive tissue culture systems: Innovative tools for toxicity testing. BIOforum Int 1999; 3: 70-2.
[98] Kloth S, Kobuch K, Domokos J, Wanke C, Monzer J. Polar application of test substances in an organotypic environment and under continuous flow: a new tissue-based test concept for a broad range of applications in pharmacotoxicity. Toxicol In Vitro 2000; 14: 265-74

[99] Frerich B, Zückmantel K, Hemprich A. Microvascular engineering in perfusion culture: immunohistochemistry and CLMS findings. Head Face Med 2006; 2: 26

[100] Frerich B, Zückmantel K, Winter K, Müller-Dürwald S, Hemprich A. Maturation of capillary-like structures in a tube-like construct in perfusion and rotation culture. Int J Oral Maxillofac Surg 2008; 37: 459-66.

[101] Kremer M, Lang E, Berger A. Organotypical engineering of differentiated composite-skin equivalents of human keratinocytes in a collagen-GAG matrix (INTEGRA Artificial Skin) in a perfusion culture system. Langenbecks Arch Surg 2001; 386(5): 357-63.

[102] Schmalz G, Garhammer P, Schweiki H. A commercially available cell culture device modified for dentin barrier test. J Endodontics 1996; 22(5): 249-52.

[103] Schmalz G, Schuster U, Nuetzel K, Schweikl H. An in vitro pulp chamber with three-dimensional cell cultures. J Endodontics 1999; 25(1): 24-9.

[104] Schmalz G, Schuster U, Thonemann B, Barth M, Esterbauer S. Dentin barrier test with transfected bovine-pulp derived cells. J Endodontonics 2001; 27(2): 96-102.

[105] Schmalz G, Schuster U, Koch A, Schweikl H. Cytotoxicity of low $\mathrm{pH}$ dentin-bonding agents in a dentin-barrier test in vitro. J Endodontonics 2002; 28(3): 188-92.

[106] Camps J, About L, Thonneman B, Mitsiadis TA, Schmaltz G, Franquin JC. Two- versus three-dimensional in vitro differentiation of human pulp cells into odontoblastic cells. Connect Tissue Res 2002; 43: 396-400.

[107] Galler K, Hiller KA, Ettl T, Schmalz G. Selective influence of dentin thickness upon toxicity of dentin contacting materials. J Endodontonics 2005; 31(5): 396-9.

[108] Demerci M, Hiller KA, Bosi C, Galler K, Schmalz G, Schweik1 H. The induction of oxidative stress, cytotoxicity and genotoxicity by dental adhesives. Dent Mat 2008; 24: 362-71.

[109] Vajrabhaya L, Korsuwannawong S, Bosl C, Schmalz G. The cytotoxicity of self-etching primer bonding agents in vitro. Oral Surg Oral Med Oral Pathol Oral Radiol Endod 2009; 107: e86-e90.

[110] Dreesmann L, Hajosch R, Ahlers M, Nuernberger JV, Schlosshauer B. Permeability testing of biomaterial membranes. Biomed Mater 2008; 3(3): 034119.

(C) Minuth et al.; Licensee Bentham Open.

This is an open access article licensed under the terms of the Creative Commons Attribution Non-Commercial License (http://creativecommons.org/licenses/by-nc/3.0/) which permits unrestricted, non-commercial use, distribution and reproduction in any medium, provided the work is properly cited. 